\title{
Interactive comment on "Trawl macrofauna of the Far-Eastern Seas and North Pacific: proportion of commercial species, potential product yield, and price range" by Igor V. Volvenko et al.
}

\section{Dirk Fleischer (Editor) \\ dfleischer@kms.uni-kiel.de}

Received and published: 30 August 2019

\section{Dear Authors,}

I do agree with the reviewers that the manuscript is worth publishing and the data set contains valuable information, but I also do agree with the review comments, that the aggregated nature of the data set does not support broad future reusability of the provided information. From the general list it is not possible to derive if the geographical distribution over this long time series has changed. There is also no information on the annual coverage of the trawl surveys in the manuscript. Again the aggregation in the provided list does not indicate if a species occurred just recently or already vanished 
30 years ago. This is all very important for future use of the dataset and I can only recommend that you should provide the raw trawl data which I believe will be used by several other scientists. I recommend to publish directly the full data matrix, but I can understand if you prefer annual - station - presence/absence lists, which would be the step in the right direction.

I hope you consider this comment valuable, because the additional value added to your manuscript would most likely result in higher reuse rate and therefore citations of your manuscript

\section{Dirk Fleischer}

Interactive comment on Earth Syst. Sci. Data Discuss., https://doi.org/10.5194/essd-2019-92, 2019. 